\title{
CRÓNICA
}

\section{XX reunión del Grupo Fomento Social}

(Madrid, 24-25 noviembre 2007)

\section{IIdefonso CAMACHO LARAÑA SJ}

Una vez más, el encuentro anual del Grupo Fomento Social se celebró en la Casa de Espiritualidad de las Esclavas del Sagrado Corazón, en Madrid (c/ General Martínez Campos), desde el viernes 23 de noviembre por la noche hasta el domingo 25 a mediodía. Los asistentes llegaron a 30 , entre ellos varios laicos que trabajan en instituciones sociales de la Compañía de Jesús. También estuvo presente en todas las sesiones el Provincial de la Compañía de Jesús en España (P. Elías Royón) y el Director del Secretariado Social de la Compañía de Jesús en Roma (P. Fernando Franco). Se encargó de la preparación de la reunión y de su desarrollo el coordinador del Grupo, P. Rafael Yuste, profesor de Ética y de Filosofía en la Facultad de Ciencias Económicas y Empresariales (ETEA) de Córdoba.

En el encuentro del pasado año se formuló el tema para el de este año de una forma general como "Democracia, transparencia y corrupción", y se subrayó el deseo de que se tratara con una perspectiva mundial. Por eso el ponente invitado para esta ocasión lo tituló "El problema mundial de la gobernanza".

\section{El tema de fondo: la gobernanza como problema mundial}

El ponente invitado fue Joan Prats Catalá, valenciano de nacimiento, pero con una larga experiencia internacional desde que se doctoró en Derecho en París. Ha sido consultor de diversos organismos internacionales en temas de gerencia y desarrollo institucional, y desde 1998 dirige el "Institut Internacional de Gobernabilitat de Catalunya". Esta institución se define como "un centro público de investigación y formación sin ánimo de lucro que produce, gestiona, aplica 
y difunde conocimiento sobre la gobernabilidad democrática para el desarrollo humano sostenible".

El contenido de su ponencia tuvo como objeto justificar el empleo de este neologismo, así como precisar su sentido. Porque la experiencia del ponente en cuestiones de desarrollo institucional le ha llevado al convencimiento de que la provisión de bienes públicos depende más de la gestión interorganizacional que de la gestión organizacional propiamente dicha. Por eso se habla cada vez más de gobierno relacional.

Gobernanza es algo más que gobernabilidad. Si ésta última depende de los propios recursos y capacidades del que gobierna, la gobernanza va más allá: es la capacidad de organizar la interacción entre actores diversos, públicos y privados, entre los que las competencias no están claramente delimitadas. La gobernanza es otra forma de gobernar, que responde mejor a las exigencias de la sociedad actual, donde los desafíos son tan enormes como complejas son las interrelaciones sociales. Porque ante esos desafíos los gobiernos se sienten hoy impotentes, por muy democráticos que sean.

$Y$ es que hoy no existe institución, por potente que sea, que posea todo el conocimiento necesario. Esta fragmentación del conocimiento es la que nos ha obligado a sustituir el plan por la gestión estratégica, la única forma de gestionar la incertidumbre. Ante esta pluralidad de actores y esta complejidad de relaciones, se impone construir una arquitectura de relaciones que permita hacer frente a los desafíos.

La gobernanza obliga a replantear la contraposición tradicional entre la esfera del sector público, que era responsabilidad de los gobiernos, y la esfera del sector privado. Porque ya los intereses generales de la sociedad no pueden ser garantizados sólo por los poderes públicos. Esta nueva situación revaloriza el papel de la sociedad civil y la importancia del ciudadano. Aun buscando sus intereses particulares, las distintas organizaciones de la sociedad civil tienen una incidencia determinante en los intereses generales de la sociedad. La gobernanza, como actitud del gobernante, implica saber coordinar todas esas interacciones sociales.

Por consiguiente, el problema de la democracia no consiste ya sólo en la modernización del aparato administrativo del Estado. Entre otras razones, porque la creciente interdependencia y globalización obliga a plantear los cauces para un gobierno mundial, lo que ya escapa a las posibilidades de los Estados. También por este camino descubrimos la importancia de la sociedad civil; y en este caso, además, de la sociedad civil mundial. 
En el diálogo que siguió a la ponencia, el ponente precisó más el concepto de gobernanza haciendo ver cómo se inspiraba en las condiciones de la "pax perpetua" de Kant: un orden de Estados libres y constitucionalmente establecidos, sin uno que ejerza la hegemonía sobre los demás. En este sentido la gobernanza global se opone al modelo de "pax americana" (basada en relaciones bilaterales) y se basa en una arquitectura policéntrica, más acorde con lo que es la realidad: en ella los gobiernos y las organizaciones sociales aprenden a colaborar, gracias también a la existencia de organismos multilaterales que ayudaran y sirvieran de cauce para consensos más amplios. En este nuevo escenario, la soberanía quedaría reducida y limitada hasta convertirse en una soberanía compartida. Al mismo tiempo habría que reorganizar los aparatos institucionales de los Estados para hacer frente al hecho de que las políticas externas y las internas cada vez están más interrelacionadas.

Por otra parte, para que esta gobernanza sea democrática es necesaria la participación de todos los afectados y en condiciones de igualdad. Desde esta perspectiva los principios de representatividad y de racionalidad tecnocrática se quedan cortos. Se hace preciso generar un espacio deliberativo donde los distintos agentes, cada uno desde su propia responsabilidad asumida, deben empeñarse en la búsqueda de consensos.

\section{La sesión de comunicaciones}

La tarde del sábado estuvo dedicada a comunicaciones diversas, que pusieran a los asistentes al corriente de diferentes iniciativas o trabajos de sus miembros.

La primera comunicación corrió a cargo del P. FERNANDO Franco, Director del Secretariado Social de la Compañía de Jesús en Roma, que habló sobre "Las ciencias sociales en la Compañía de Jesús". Comenzó analizando la crisis que sufren hoy las ciencias sociales, que están perdiendo el protagonismo de otros tiempos, especialmente la actividad investigadora. Recordó la actuación de los Centros de Investigación y Acción Social (CIAS), que se desarrollaron sobre todo en América Latina desde los años 1950. Deploró también la desvinculación progresiva que se había producido en la Compañía entre el sector social y el universitario.

Pero esta comunicación tenía por objeto más bien dejar constancia del renacido interés actual por la investigación social como un complemento esencial a los programas de incidencia. Con objeto de dar cauces a este interés renovado propuso 
elaborar un plan estratégico supraprovincial a 3-5 años que estableciera algunos temas prioritarios y comunes para cada región y creara equipos investigadores con una fuerte participación de laicos, siempre vinculados a centros universitarios, pero a través de institutos que gozaran de una cierta autonomía de acción.

En una segunda comunicación, DANIEL IZUZQUIZA presentó un informe sobre la Semana Social Europea, organizada por los jesuitas del continente y celebrada en Bratislava en agosto de 2007. El tema abordado fue: "Hacia una espiritualidad común en el apostolado social". Destacó la relevancia que el tema va adquiriendo entre los distintos grupos que trabajan en este campo y que buscaron puntos de convergencia en los días que duró el encuentro: Misión Obrera, Eurojess (Jesuitas Europeos en Ciencias Sociales), Servicio Jesuita de Refugiados. Para llegar a estas convergencias se analizaron diversas experiencias fundantes y se prestó especial atención a los momentos de crisis y transformación. El encuentro en sí fue valorado por muchos como una verdadera experiencia espiritual.

La comunicación de Alberto Guerrero, jesuita que trabaja en Valencia, fue titulada por su autor "De la cooperación asistencialista y el timo del codesarrollo a la cooperación para el desarrollo humano con evaluación de gobernanza". Habló desde su experiencia internacional en Nicaragua, en Burundi y ahora en Valencia. Esa experiencia le lleva al convencimiento de que la Compañía de Jesús puede colaborar al buen gobierno del mundo, sobre todo allá donde no hay otras vías para ello.

En su comunicación, ILDEFONSO CAMACHO, de la Facultad de Teología de Granada, informó sobre el reciente encuentro sobre "La ética en la vida pública", organizado por el Grupo de Ética de las Profesiones de UNIJES (Centros universitarios de la Compañía de Jesús en España) y celebrado en Cercedilla (Madrid) en septiembre de 2007'. En él se pretendió generar un debate intelectual y articular una plataforma multidisciplinar desde la que contribuir a la ética de la vida pública y al modo de valorar las actuaciones de los principales agentes de la misma. Para ello se analizaron los tres agentes principales de la vida pública: el político, el funcionario y el ciudadano. Previamente se trabajó en definir lo que era el espacio propio de la vida pública, diferenciándolo de otros con los que las fronteras no siempre son nítidas. Por último y como reflejo de la identidad de los centros organizadores, se abordó el papel de la Iglesia en la vida pública y el que corresponde más concretamente a un centro universitario de inspiración cristiana.

1 Una crónica de dicho simposio ha sido publicada en Revista de Fomento Social 62 (2007) 463-473. 
La última comunicación de la tarde corrió a cargo de RAúl GoNZÁlEZ, jesuita de la provincia venezolana que imparte actualmente cursos de ética en la Universidad Pontificia Comillas. El tema: "Corrupción en América Latina". Mostró cómo las estructuras políticas institucionales modernas han sido superpuestas a redes relacionales preexistentes, pero no han llegado a sustituirlas. De este modo, por detrás de las instituciones de la democracia sigue funcionando ese sistema ancestral, gracias al cual es posible torcer la ley y eludir su cumplimiento. En este contexto apenas cabe hablar de corrupción, lo que supondría que algo que funcionó bien se degeneró a partir de un momento: aquí nada llegó a funcionar efectivamente como indica la teoría política moderna. En realidad esas estructuras culturales antiguas siguen vivas y han sido capaces de colonizar por dentro las estructuras modernas.

\section{Otros informes}

La mañana del domingo comenzó con la presentación de tres informes complementarios a lo tratado en la tarde anterior.

En primer lugar, JOSEP MÀRIA, que trabaja en ESADE (Barcelona), informó sobre el encuentro de Eurojess, celebrado a continuación del encuentro arriba reseñado y en el mismo lugar que aquél (Bratislava). En esta ocasión el tema escogido fue: "Trabajo y paro en Europa". El nuevo contexto de la globalización fue determinante para todas las reflexiones. Las ponencias fueron complementadas con talleres que desarrollaron tres experiencias: ¿¿cómo trabajar para rehacer un barrio marginal de París?, trabajo y mundo gitano, jóvenes y trabajo. El próximo encuentro, que se celebrará probablemente en Granada, se ocupará de la presencia del Islam en Europa.

El Delegado del Sector Social de los jesuitas de Italia, GiovanNi LA MANA, presentó las novedades más señaladas del "Jesuit Social Network", de lo que ya informó el año pasado en este encuentro. Destacó la valiosa aportación de los laicos a esta red y a todas las instituciones que se integran en ella. Y subrayó también la necesidad creciente de diálogo con los centros jesuitas de investigación social (Milán y Palermo, concretamente) para estrechar la colaboración.

Por último intervino BRENDAN MAC PARTIN, que acaba de ser nombrado Delegado para el Sector Social del Presidente de los provinciales jesuitas de Europa. Expuso sus primeras impresiones después de los contactos mantenidos hasta ahora y su convencimiento creciente de que hay respetar el trabajo local y reconocer esas 
energías. Pero no excluyó la conveniencia de hacer algo a nivel europeo, teniendo muy en cuenta las prioridades y retos del continente.

\section{Asamblea estatutaria del Grupo}

La parte central de la asamblea estatutaria del Grupo la ocupó la elección de nombres para ser propuestos como posibles coordinadores del mismo. Ello dio ocasión para reflexionar sobre la historia de este colectivo y su función en el momento actual. La votación tuvo carácter indicativo y los nombres más votados fueron transmitidos al Provincial de España para que él procediera al nombramiento definitivo².

La elección del tema para el encuentro del próximo año (que se celebrará el fin de semana 28-30 de noviembre) comenzó con una larga enumeración que respondía a distintos intereses de los participantes. Buscando ciertas líneas de convergencia entre las diferentes propuestas se formuló el tema como: "Catalizadores de la acción social: agentes estratégicos frente a los técnicos que asesoran y a los políticos que legitiman".

${ }^{2}$ En el momento de redactar esta crónica el P. Provincial de la Compañía de Jesús en España ha nombrado ya Coordinador del Grupo a José María Margenat (de ETEA, Córdoba). 